\title{
Correction to: MiR-10a-5p targets TFAP2C to promote gemcitabine resistance in pancreatic ductal adenocarcinoma
}

Guangbing Xiong ${ }^{1,2 \dagger}$, Hua Huang ${ }^{1 \dagger}$, Mengyu Feng ${ }^{1 \dagger}$, Gang Yang ${ }^{1 \dagger}$, Suli Zheng ${ }^{1}$, Lei You', Lianfang Zheng ${ }^{3}$, Ya Hu', Taiping Zhang ${ }^{1,4^{*}}$ and Yupei Zhao ${ }^{1 *}$

Correction to: J Exp Clin Cancer Res 37, 76 (2018)

https://doi.org/10.1186/s13046-018-0739-x

Following publication of the original article [1], the authors identified minor errors in Fig. 2; specifically, in Fig. 2b, in the fourth group, the invasion, SU86.86, inhibitor images have been replaced with the correct images.

The corrected figure is provided here. The correction does not have any effect on the results or conclusions of the paper. The original article has been corrected.
Published online: 18 November 2021

\section{Reference}

1. Xiong $\mathrm{G}$, Huang $\mathrm{H}$, Feng $\mathrm{M}$, et al. MiR-10a-5p targets TFAP2C to promote gemcitabine resistance in pancreatic ductal adenocarcinoma. J Exp Clin Cancer Res. 2018;37:76. https://doi.org/10.1186/s13046-018-0739-x.

\section{Author details}

'Department of General Surgery, Peking Union Medical College Hospital, Chinese Academy of Medical Sciences and Peking Union Medical College, No. 1 Shuaifuyuan, Wangfujing Street, Beijing 100730, China. ${ }^{2}$ Department of Biliary-Pancreatic Surgery, Affiliated Tongji Hospital, Tongji Medical College, Huazhong University of Science and Technology, Wuhan 430030, Hubei Province, China. ${ }^{3}$ Department of Nuclear Medicine, Peking Union Medical College Hospital, Chinese Academy of Medical Sciences and Peking Union Medical College, Beijing 100730, China. ${ }^{4}$ Clinical Immunology Center, Chinese Academy of Medical Sciences and Peking Union Medical College, No. 1 Shuaifuyuan, Wangfujing Street, Beijing 100730, China.

The original article can be found online at https://doi.org/10.1186/s13046018-0739-x.

\footnotetext{
*Correspondence: tpingzhang@yahoo.com; zhao8028@263.net

${ }^{\dagger}$ Guangbing Xiong, Hua Huang, Mengyu Feng and Gang Yang contributed equally to this work.

1 Department of General Surgery, Peking Union Medical College Hospital, Chinese Academy of Medical Sciences and Peking Union Medical College, No. 1 Shuaifuyuan, Wangfujing Street, Beijing 100730, China

${ }^{4}$ Clinical Immunology Center, Chinese Academy of Medical Sciences and Peking Union Medical College, No. 1 Shuaifuyuan, Wangfujing Street, Beijing 100730, China

Full list of author information is available at the end of the article
}

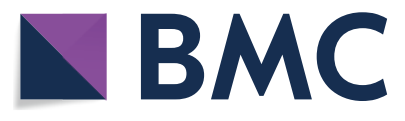

(2021. Open Access This article is licensed under a Creative Commons Attribution 4.0 International License, which permits use, sharing, adaptation, distribution and reproduction in any medium or format, as long as you give appropriate credit to the original author(s) and the source, provide a link to the Creative Commons licence, and indicate if changes were made. The images or other third party material in this article are included in the article's Creative Commons licence, unless indicated otherwise in a credit line to the material. If material is not included in the article's Creative Commons licence and your intended use is not permitted by statutory regulation or exceeds the permitted use, you will need to obtain permission directly from the copyright holder. To view a copy of this licence, visit http://creativecommons.org/licenses/by/4.0/. The Creative Commons Public Domain Dedication waiver (http://creativeco mmons.org/publicdomain/zero/1.0/) applies to the data made available in this article, unless otherwise stated in a credit line to the data. 


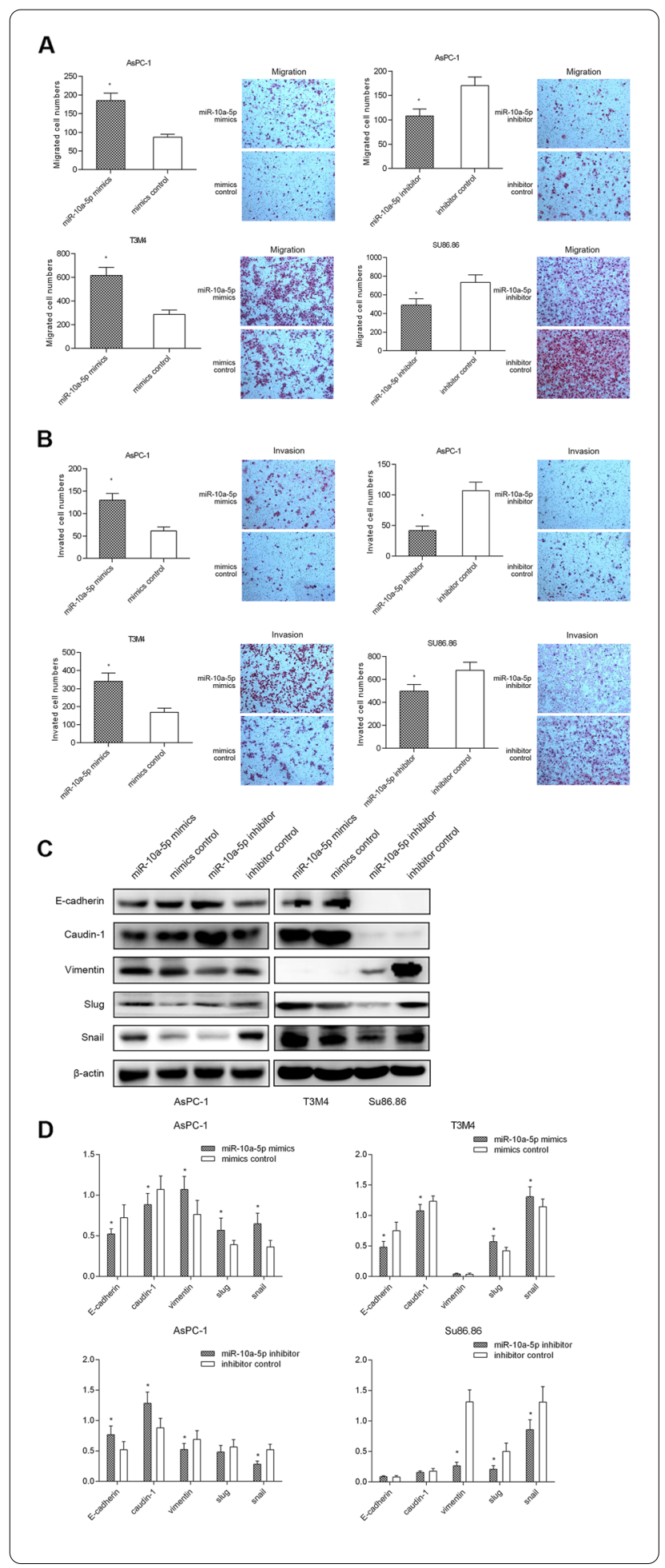

Fig. 2 MiR-10a-5p promotes PDAC cell migration and invasion. a MiR-10a-5p overexpression promoted T3M4 and AsPC-1 cell migration, while miR-10a-5p knockdown decreased Su86.86 and AsPC-1 cell migration; $\mathbf{b}$ miR-10a-5p overexpression promoted T3M4 and AsPC-1 cell invasion, while miR-10a-5p knockdown decreased Su86.86 and AsPC-1 cell invasion; c miR-10a-5p expression up-regulation decreased E-cadherin and Caudin-1 protein levels while increasing Vimentin, Slug and Snail levels, as determined by using western blotting. $\mathbf{d}$ The relative intensity of the grayscale band values revealed the changes with miR-10a-5p overexpression or knockdown in PDAC cells; the data are presented as the means \pm SD (Student's t-test; ${ }^{*}, P<0.05$ ) 